\title{
BMJ Open Psychiatric epidemiological survey of university students in Botswana: rationale and methods of the Youth Mental Health Study (YMHS)
}

\author{
J Maphisa Maphisa (D), Opelo Petunia Mogotsi, Olorato Khumo Machola, \\ Keamogetse Metlha Maswabi, Tiro Bright Motsamai, Boitshepo Mosupiemang
}

To cite: Maphisa JM, Mogotsi OP, Machola OK, et al. Psychiatric epidemiological survey of university students in Botswana: rationale and methods of the Youth Mental Health Study (YMHS). BMJ Open 2020;10:e038175. doi:10.1136/ bmjopen-2020-038175

- Prepublication history and additional material for this paper are available online. To view these files, please visit the journal online (http://dx.doi. org/10.1136/bmjopen-2020038175).

Received 02 March 2020 Revised 26 May 2020 Accepted 16 July 2020
Check for updates

(c) Author(s) (or their employer(s)) 2020. Re-use permitted under CC BY-NC. No commercial re-use. See rights and permissions. Published by BMJ.

Department of Psychology, University of Botswana, Gaborone, Botswana

Correspondence to J Maphisa Maphisa; maphisa.maphisa@mopipi. ub.bw

\section{ABSTRACT}

Background While the burden of disease attributable to mental disorders in low/middle-income countries (LMICs) is lower than high-income countries, there is recognition that the dearth of evidence from the LMICs may underestimate the actual prevalence and burden associated with mental disorders. Such is likely the case for Botswana where there has been no nationally representative data on the prevalence of symptoms of mental disorders or even a subgroup estimation of mental disorders in the country. Thus, the Youth Mental Health Study (YMHS) aims to estimate the prevalence and identify predictors of symptoms of mental disorders among university students in Botswana to add to the evidence and contribute to the country's health service planning. Methods The YMHS is a cross-sectional study of youth (18-29 years) attending six large universities (accounting for nearly half of the tertiary student population) in Botswana. A stratified sampling procedure with proportionate allocation and selection is used to select a representative sample of 1308 participants. An online survey comprising of a battery of reliable and validated self-report measures of symptoms of mental disorders is used. A developmental psychopathology framework is used in identifying the risk factors of mental disorders. Participant recruitment will span over 4 months beginning in February 2020.

Ethics and dissemination The study has received ethics approval from the University of Botswana Institutional Review Board, and the Ministry of Health and Wellness. Participants will be provided with feedback of their own results. Aggregated findings will be disseminated to stakeholders in the tertiary education and health sector in Botswana, and through peer-reviewed journals, conference presentations and the media.

\section{INTRODUCTION}

Robust healthcare service planning requires information on the distribution of diseases and their aetiologies to ensure that appropriate healthcare is delivered to the appropriate population and at the appropriate time. ${ }^{1}$ For low/middle-income countries (LMICs), like Botswana, uninformed service
Strengths and limitations of the study

- This is Botswana's first study of the wide breadth of symptoms of mental disorders among a representative sample of an important group.

- The use of a stratified sampling procedure with proportionate allocation increases the representativeness of the sample.

- An online survey method minimises costs and maximises participant anonymity and ease to participate.

- Despite use of a developmental theory to determine predictors across the lifespan, the study is cross sectional and relies on retrospective recall vulnerable to bias

- The instruments used are not diagnostics but provide participants' reported experiences of symptoms of mental disorders.

planning threatens the utility of the already limited healthcare budget. This state of affairs affects mental health services even more given the low government spending for mental healthcare ${ }^{2}$ despite the high burden of disease associated with psychiatric illness. ${ }^{3}$ Thus, studies on the prevalence and predictors of symptoms of mental disorders in LMICs are even more important to conduct. ${ }^{4}$ Despite this need, there is no nationally representative data on the prevalence of symptoms of mental disorders in Botswana, nor is there a subgroup estimation of mental disorders in the country.

The more robust of the available studies is a cross-sectional population study ${ }^{56}$ which investigated depressive symptoms among a sample of 1268 participants from five of the 17 districts in the country. The study found a $28 \%$ prevalence of significant depressive symptoms as measured by the Hopkins Symptom Checklist for Depression. ${ }^{6}$ Other available studies in Botswana are mostly disorder specificmostly depressive symptoms ${ }^{78}$; are restricted 
to specific clinical populations-mostly $\mathrm{HIV}^{69}$; and offer a cross-sectional formulation of symptoms of mental disorders-for example, proximal psychological variables. ${ }^{8} 10$ Resource constraints may limit the undertaking of the much-needed representative epidemiological studies which explore the breadth of 'mental systems' and are not just restricted to a single mental disorder. Thus, as an intermediary step to such ideal studies, focusing on specific subgroups of the population, particularly vulnerable to psychopathology, like the youth, can be considered as a starting point. The Youth Mental Health Study (YMHS) aims to address this challenge by focusing on youth attending university in Botswana.

The majority of mental disorders present no later than young adulthood, ${ }^{11}$ and the 12-month prevalence of any mental disorder among young adults aged 19-25 years in other countries has been found to be as high as nearly $50 \% .{ }^{12}$ While there are inconsistent results (some studies find greater risk ${ }^{1314}$ while others do not finding greater risk,${ }^{12}{ }^{15}$ ) about whether university students are at greater risk of mental disorders, what is clear from the available studies is that a significant number of students have mental disorders. Two recent cross-country studies, ${ }^{15}{ }^{16}$ which included LMICs like Nigeria and South Africa, found the pooled prevalence of mental disorders to be between $20 \%$ and $31 \%$ of participating students. However, in one of the two studies, the country-specific prevalence rates ranged from $19 \%$ (Belgium) to $43 \%$ (Australia). ${ }^{16}$ This range in prevalence rates highlights the need for country-specific epidemiological investigations. Thus, the proposed YMHS aims to address this need in the context of Botswana.

Unipolar depression is the most prevalent disorder among university students. ${ }^{16-18}$ In Botswana, non-random small studies have found that between $40 \%^{7}$ and $55 \%^{8}$ of university students in their earlier 20 s screen positive for depression (Beck Depression Inventory score of 14 and above). A systematic review of predictors of depression among university students has shown that depressive symptoms are predicted by multiple biopsychosocial variables. ${ }^{19}$ It is notable that there are university-specific stressors which precipitate or exacerbate psychopathology. ${ }^{70}$ Internalising disorders like depression, in turn, have immediate negative consequences on students' academic performance. ${ }^{21}$ Compromised academic achievement due to mental illness significantly undermines the developmental agenda of LMICs like Botswana whose increasing number of youth transitioning into tertiary education ${ }^{17}$ is a precondition/ tied to socioeconomic prosperity. ${ }^{22}$ Therefore, targeting university students provides an opportunity for a focused investigation of the mental health functioning among an important subgroup of the population. Furthermore, the findings of the study are more likely to lead to swifter provision of mental healthcare services since the universities have student health and wellness centres. Additionally, the findings will serve to inform randomised clinical trials in the field of mental health by establishing target syndromes requiring intervention. Therefore, detecting, preventing and treating mental disorders among young adults, particularly university students, can contribute in the reduction of the overall population burden of mental disorders, and improve students' well-being during their studies.

Heeding to the need for psychiatric epidemiological surveys to estimate the prevalence and identify modifiable risk factors, ${ }^{23}$ the YMHS has two broad objectives. First, it seeks to estimate the current (past 2 week) prevalence of symptoms of mental disorders among youth (18-29 years of age) attending university in Botswana. Second, it aims to determine the demographic and developmental (incl. biopsychosocial) factors associated with the symptoms of mental disorders. The study uses the developmental psychopathology theory to identify likely predictors of mental disorders. The theory contends that psychopathology arises over time within an active, developing organism and is an outcome of multiple pathways (ie, equifinality) ranging from molecular to social systems. ${ }^{24}{ }^{25}$ Guided by the developmental psychopathology framework, ${ }^{24}$ we hypothesise that a constitution of distal and proximal factors will predict the presence of mental disorders. However, the concepts of equifinility and multifinility, cautions against rigid hypotheses given that there are inherently multiple pathways to the development of disorder, and the exposure to 'risk factors' does not invariably lead to psychopathology. ${ }^{24} 25$

Based on previous research, the following risk factors over and above demographic variables will be assessed: (1) family history of mental illness (as proxy for heredity), (2) parenting style, (3) adverse childhood experiences (ACE), (4) personal income, (5) history of psychiatric illness; (6) physical health, (7) intimate partner conflict, (8) reflective ability, (9) academic performance, and (10) adjustment to university. Substance use motives are further assessed among substance users. As displayed in figure 1, although these variables can be divided into childhood, adolescence and adulthood, it should be noted that some of the variables cut across developmental stages.

\section{METHODS}

\section{Study design}

The YMHS is a multisite cross-sectional study employing an online survey method.

\section{Setting}

Participants are drawn from six universities (equal number of private and public universities) in Botswana. Botswana is a southern African country with a population of 2 million people, majority being youth. ${ }^{26}$ One in five youth aged 18-24 years are enrolled in tertiary education institutions. ${ }^{27}$ The six participating institutions represent $46 \%$ of the student enrolment in tertiary education institutions in the entire country.

\section{Sampling procedure}

A stratified sampling method with a proportionate allocation is used to sample participants from six large, 

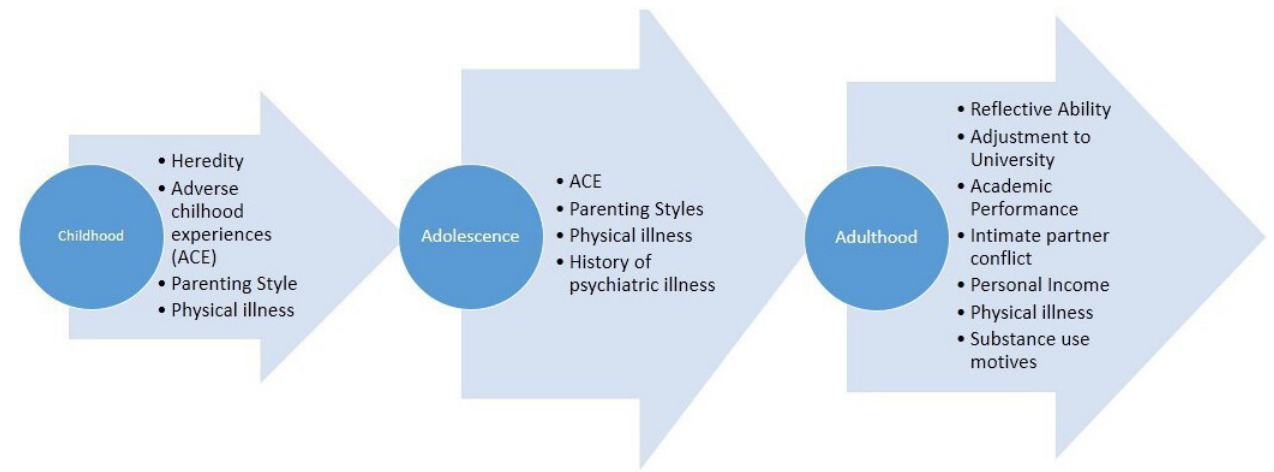

Figure 1 Risk factors across the lifespan.

conveniently selected universities in Botswana. The number of participants sampled from each university is proportionate to each university's headcount relative to the combined headcount of the six universities. However, a final minimum sample from the respective universities is set at 150 participants. Addition of participant numbers is done without redistribution to ensure the minimum 150 participants per university. Each university is then stratified by gender and level of academic study and a proportionate allocation to strata is conducted based on the two variables. The levels of academic study are: first year, second year, third year, fourth year, fifth year, Masters and PhD. The number of strata differ across the universities because the universities offer programmes at differing levels. The number of strata in each institution ranges from 8 (universities with only 4 year undergraduate degree programmes) to 14 (one university with 5-year undergraduate programmes, and with an offering up to $\mathrm{PhD}$ ). From the stratified sample frame, students in each strata are proportionately selected using random numbers generated by Microsoft Excel. The total number of invited students will take into account a non-response rate of $60 \%$ based on previous studies using online questionnaires. ${ }^{1628} 29$

\section{Sample size}

The total final sample size sought for this study is 1308 participants. The sample distribution of the sites of interest is presented in table 1 .

The sample size was calculated using Cochran's (1977) formula:

$$
\mathrm{n}=\mathrm{n}_{0} /\left(1+\mathrm{n}_{0} / \mathrm{N}\right)
$$

where $n$ is the sample size, $N$ is population size (total tertiary education student enrolment less public vocational and technical institutions $=48$ 230) and $n_{0}$ is based on $95 \%$ level of confidence.

And

$$
\mathrm{n}_{0}=\frac{\mathrm{z}_{1-\frac{\alpha}{2}}^{2} \mathrm{P}(1-\mathrm{P})}{\mathrm{e}^{2}} * \text { Deff }
$$

where $p=$ prevalence rate of $30 \%$ based on recent international estimates of mental disorders among university students ${ }^{16} ; Z^{2}-\alpha / 2=(1.96)^{2}$ for $95 \%$ confidence $(\alpha=0.05) ; \mathrm{e}=$ maximum tolerable error for the prevalence estimate $=0.03$; and Deff=design effect $=1.5$. The formula was corrected using a Deff given multistage sampling used in this study.

Thus,

\begin{tabular}{|c|c|c|c|c|}
\hline Institution & Enrolment* & $\begin{array}{l}\text { Proportional sample } \\
\text { size }\end{array}$ & $\begin{array}{l}\text { Adjusted sample } \\
\text { size }\end{array}$ & $\begin{array}{l}\text { Invited sample } \\
\text { size† }\end{array}$ \\
\hline \multicolumn{5}{|l|}{ Public universities } \\
\hline $\begin{array}{l}\text { Botswana University of Agriculture and } \\
\text { Natural Resources }\end{array}$ & 1282 & 61 & 150 & 375 \\
\hline Ba Isago University & 2352 & 112 & 150 & 275 \\
\hline Boikanelo College & 2255 & 108 & 150 & 375 \\
\hline Botho University & 4430 & 212 & $\mathrm{n} / \mathrm{a}$ & 530 \\
\hline Total & 27390 & 1308 & & 3493 \\
\hline
\end{tabular}

Table 1 Sample distribution of the sites of interest

${ }^{*}$ Enrolment numbers are from the HRDC. ${ }^{27}$

†Number based on a response rate of $40 \%$. 


$$
n_{0}=\frac{Z_{\frac{\alpha}{2}}^{2}(\rho)(1-\rho)}{\delta^{2}} * \text { Deff }=\frac{1.96^{2}(0.3)(1-0.3)}{(0.03)^{2}} * 1.5=1344.56
$$

Therefore,

$$
\mathrm{n}=\frac{1344.56}{1+\frac{1344.56}{48230}}=1308
$$

\section{Data collection}

Platform: data are collected and managed through Research Electronic Data Capture (REDCap) which is hosted by the University of Botswana. REDCap is a secure web application for building and managing online surveys and databases developed by Vanderbilt University. ${ }^{30} 31$ Once a questionnaire is built on REDCap, survey invitation links are generated for delivery to participants whose responses can be exported to different statistical packages for analysis. ${ }^{30}$ REDCap currently has over 3200 partners and it continues to be used internationally for online research and database management. ${ }^{31}$ Using REDCap is cost effective for researchers and is convenient and more anonymous for participants in that it allows participants to attempt the online questionnaire privately at their own time and pace. Additionally, REDCap's 'save and return later' option allows participants to pause and continue with the questionnaire at a different time without losing their information.

Procedure: the YMHS research team built the questionnaire on REDCap for about 2 weeks. The questionnaire was tested by the team and then piloted among 160 university students. Feedback from the pilot was used to make minor adjustments (mostly skip logic corrections). Participants are invited via email and text messages, and thereafter receive fortnightly reminders for 4 months. Reminders also contain their return codes so that they can access the questionnaire from where they paused. Participants who complete the questionnaire have an option to request their results which are generated via Microsoft Excel and sent via email. Participants whose profiles indicate a need for mental health intervention are also contacted through voice calls to ensure that they can access such services.

Instruments: the questionnaire is a battery of 270 items which takes at most 50 minutes to complete. Given the skip logics embedded in the questionnaire, there is variability in completion time. The questionnaire is divided into three levels of enquiry. In the first level, participants are screened for symptoms of eight mental disorders and suicidality. The second level comprises disorder-specific screening tools. The prevalence of significant symptoms of mental disorders is determined by each of these disorder specific screening tools in level 2. A participant's results on the first level tool directs them to indicated, disorderspecific screening measures. The third level is completed by all participants, and it assesses developmental factors and demographic factors associated with mental disorders. Online supplemental appendix A provides a tabular presentation of structure of the questionnaire.
Level 1: overall screening of domains of mental disorders. In-depth structured clinical interviews like the Structured Clinical Interview for the DSM 5 (SCID) and the Composite International Diagnostic Interview (CIDI) remain the golden standard to establish the presence of mental disorders in surveys. However, the logistical and cost implications of these interviews have seen a rise in the development of briefer and affordable screening tools with comparable results to the SCID and CIDI ${ }^{23}$ In fact, one of the largest ongoing WHO studies on the university students' mental health has adopted such screening tools. ${ }^{32}$

For this study, we adapted the American Psychiatric Association (APA) Level 1 cross-cutting symptom measure (L1-CCSM). Originally, the L1-CCSM has 23 items assessing 13 domains of psychopathology. However, for purposes of this study, four domains (sleep problems, memory, dissociation and personality functioning) were removed given the difficulties with screening them further. We added another domain to investigate experience of traumatic events. Additionally, we amended the suicidal ideation question to read 'Thoughts of actually hurting or killing yourself'. The adapted measure has 17 items assessing the following nine domains: depression, mania, anxiety, somatic symptoms, suicidal ideation, psychosis, repetitive thoughts and behaviours, traumatic experiences and substance use. Fifteen items are rated on a 5-point Likert scale (ranging from 0, 'none' to 4, 'severe') with a lower number indicating less frequency or severity and the higher number indicating the highest frequency or severity of symptoms. ${ }^{33}$ The response to substance use items and the history of trauma item is a dichotomous Yes or No. A score of 2, 'mild', or greater or a yes response to the substance use and history of traumatic events items will be used to redirect the participants for further assessment using disorder-specific measures.

Studies have confirmed the use of the L1-CCSM measure for identification of different psychiatric presentations. ${ }^{34-36}$ In a study with university students, the measure had a good internal validity and concurrent validity. ${ }^{34}$ Test-retest reliability of the measure was good in a study with adults. ${ }^{35}$

Level 2: disorder-specific assessment. Based on their results (2, 'mild', or more, and Yes) at the level 1 tool, participants complete disorder-specific screening measures. These measures are used to confirm the presence of significant symptoms of mental disorders. For example, if a participant scored 2 or more on the depression items of the L1-CCSM, they will be directed to the Patient Health Questionnaire depression module, $\mathrm{PHQ}-9^{37}$ for further assessment. For ease of presentation, online supplemental appendix B details the respective measures and their psychometric properties.

Depressive symptoms. A score of 10 and above on the PHQ-9 is used as an indication of the presence of significant depressive symptoms. ${ }^{37}$ 
Manic symptoms. A score of 6 and above on the Altman Self-Rating Mania Scale indicates significant manic symptoms. ${ }^{38}$

Anxiety symptoms. Three types of anxiety disorders are explored in this study: generalised anxiety, panic and social anxiety. Determination of the presence of the respective significant symptoms is based on the following markers: a score of 10 or more on the Generalised Anxiety Disorder Assessment, ${ }^{39}$ a score of 20 on the APA panic severity measure, and a score of 6 or more on the MiniSocial Phobia Inventory (Mini-Spin). ${ }^{40}$

Somatic symptoms. The 15-item Patient Health Questionnaire Physical Symptom module (PHQ-15) is used to measure significant somatic symptoms, with a score of 10 as a cut-off point. ${ }^{41}$

Obsessive-compulsive symptoms. A score of 8 or more on part B of the Florida Obsessive-Compulsive Inventory determines significant symptoms. ${ }^{42}$

Post traumatic stress (PST) symptoms. PST symptoms are measured using the nine item National Stressful events Survey for post-traumatic stress disorder Short Scale, and a cut-off of 18 is used. ${ }^{43}$

Suicidality and Self-harm. Suicidality is assessed through questions adapted from the Columbia Suicide Severity Rating scale ${ }^{44}$ covering the following: (1) frequency and onset of suicidal ideation and attempts, (2) methods used in suicide attempts, and (3) injuries sustained during attempts. Participants indicate self-harm methods and onset of self-harm from a list of 10 methods derived from Whitlock et $a l^{45}$.

Substance use disorders. The following substances or their classes are explored: alcohol, cannabis, cocaine, hallucinogens, heroin, inhalants, methamphetamine, prescription opioids, sedatives and tobacco. Probable alcohol use disorder is assessed by the Alcohol Use Disorder Identification Test, using eight as a cut-off score. ${ }^{46}$ Probable Cannabis Use Disorder is determined by a score of 13 or more on the Cannabis Use Disorder Identification Test Revised. ${ }^{47}$ Other substance use disorders are determined by a substance involvement score of 4 or more on the National Institute of Drug Abuse Alcohol, Smoking, and Substance Involvement Screening Test. ${ }^{48}$

Level 3: associated variables. These variables have been selected to assess the factors associated with symptoms of psychopathology. The choice of these measures were informed by the developmental perspective to psychopathology in which psychopathology is viewed from a longitudinal stance and within the context of life-span development. ${ }^{24}$ The variables explored include: (1) family history of mental illness (as proxy for heredity), (2) parenting style, (3) ACE, (4) personal income, (5) history of psychiatric illness; (6) physical health, (7) intimate partner conflict, (8) reflective ability, (9) academic performance, and (10) adjustment to university. The 15 item Measure of Parenting Styles is used to assess dysfunctional parenting styles: indifference, abusive and overcontrolling. ${ }^{49}$ ACE in the home, among peers, and within the community are measured by the Adverse Childhood
Experiences International Questionnaire. ${ }^{50}$ Participants are to indicate the following relating to personal income: source of income and adequacy of the income to cover living expenses. All participants indicate in two items if they have ever been diagnosed with any chronic physical illness and mental illness. Participants identifying as female complete three obstetric history items (ever been pregnant, number of pregnancies and live children, and ever undergone a termination of pregnancy). Twelve items from the Conflict Tactics Scale Short Form are used to measure intimate partner relationship conflict. ${ }^{51}$ Reflective ability, that is, the ability to make interpretations about the self and others based on one's understanding of the mental states of the self and others is measured using the eight item Reflective Functioning Questionnaire. ${ }^{52}$ Academic performance is measured via self-reported Grade Point Average (GPA) and history of failing courses. Eight items from the Student Adjustment to College Questionnaire assess academic adjustment, social adjustment, personal/emotional adjustment and attachment. ${ }^{53}$ Substance-using participants are asked 13 substance use motives adapted from the Drinking Motives Questionnaire-Revised. ${ }^{54}$ Additionally, participants complete items requesting their age, gender (female, male, transgender, gender neutral, other), sexual orientation (Heterosexual, Homosexual, Bisexual, Other), relationship status (Single, in romantic relationship with one partner, in romantic relationship with more than one partner, Married, Separated, Divorced, Widowed), religious affiliation (Christianity, Islam, Buddhism, African Traditional Religion, Other, None) and place of upbringing (City, Town, Village, Cattle post).

The specific measures and their psychometric properties are described in online supplemental appendix B.

\section{Quality control}

Data obtained during the survey are collected and managed using REDCap, a platform developed in accord to the HIPAA-Security guidelines. Data not yet extracted remains stored on the University of Botswana Department of Computer Science servers where access is restricted and auditable. Once data are extracted for analysis, it will be stored in a password-protected electronic format.

\section{Analysis plan}

The questionnaire responses are extracted from the online questionnaire portal and analysed using Statistical Package for Social Sciences- V.25. ${ }^{55}$ Preliminarily, an assessment of participation bias is conducted to evaluate the sample distribution in terms of gender and academic level. Following this assessment, data are weighted to adjust for any residual discrepancies between the sample and the population based on gender and level of academic study. Aggregated estimates (incl. 95\% CIs) of prevalence of significant symptoms of mental disorders will be calculated. Cross tabulations will be used to calculate decomposed estimates of the prevalence, with 95\% CI, of each domain of mental disorders by gender, and 
level of study. Multivariate analyses (a logistic regression analysis) will be computed to identify the demographic and developmental predictors of symptoms of mental disorders based on disorder specific measures. Logistic regression coefficients and standard errors will be exponentiated to produce ORs with $95 \%$ CI. Statistical significance of all analyses is set at the 0.05 level.

\section{Patient and public involvement}

Stakeholder engagements were conducted jointly on the 12 September 2019 with university students via their Student Representative Councils (SRCs) and relevant personnel from the participating universities. Individual consultations were further held with senior personnel from the participating universities and with the ministry responsible for tertiary education in the country. The proposed study was described to them with the aim of getting their input on how to refine the study to ensure that respective interests were addressed. The stakeholders were receptive to the study and showed enthusiasm and support . The following were added to the questionnaire following deliberation: an extensive substance use module and questions on barriers to accessing mental health services. Stakeholders also requested that individual participant's feedback about their mental health be availed only at the request of the participant rather than automatically. Stakeholders further suggested that the research team use the dissemination workshops to provide a platform to conceptualise a mental health policy and plan relating to university students in Botswana.

\section{ETHICS AND DISSEMINATION}

The YMHS received ethics approval from the University of Botswana's Institutional Review Board and from the Ministry of Health and Wellness (Reference number: HPDME:13/18/1). The study was developed and is implemented in compliance with the Declaration of Helsinki. ${ }^{56}$

Participants receive an invitation detailing the study and assuring them of confidentiality and the voluntary nature of the study, risks of harm, and the opportunity to withdraw at any time during the course of the administration. Given the likely risk of psychological distress while completing the questionnaire, students are provided with contact numbers of mental health service providers. Students are referred to their respective University Counseling Centers, Psychology Psychiatric Units in hospitals across the country, and University of Botswana Psychology Clinic (which offers free psychological services to university students and the general public) if they feel distress after sharing information about mental health-related symptoms. The survey invitation includes a hyperlink directing participants to the survey. Clicking on the link and proceeding to complete the questionnaire will therefore imply that participants have read, and they give informed consent to participate in the study.

Dissemination of the research findings is done at three levels. At the participant level, each participant will receive results relating to their mental health functioning. These results are sent via email. As part of the feedback, participants are advised on service provider options. At the institutional level, aggregated results are shared with relevant university personnel (eg, university Student Affairs personnel include: counselling units; and SRCs) to consider how their mental health service and student welfare provision could be adjusted in light of the results. In addition to university personnel, the following stakeholders will be given feedback: Ministries of Tertiary Education, Health and Wellness, and Youth in Botswana. Policy briefs will also be shared with these local stakeholders. Based on results of the study, mental health literacy products (brochures, posters, a mobile phone application, and a study Facebook page) will be produced for dissemination in the universities and beyond.

Since this is an inaugural study into mental health functioning among youth in Botswana, publication of the study findings will fill an important research gap. The study findings will be published in the form of scholarly articles and presented at regional and international conferences.

Contributors JMM and OPM conceptualised and designed the study. All authors piloted the study, revised the data collection instruments, conducted the public engagements, and produced the initial draft and final manuscript.

Funding The authors have not declared a specific grant for this research from any funding agency in the public, commercial or not-for-profit sectors.

Competing interests None declared.

Patient consent for publication Not required.

Provenance and peer review Not commissioned; externally peer reviewed.

Supplemental material This content has been supplied by the author(s). It has not been vetted by BMJ Publishing Group Limited (BMJ) and may not have been peer-reviewed. Any opinions or recommendations discussed are solely those of the author(s) and are not endorsed by BMJ. BMJ disclaims all liability and responsibility arising from any reliance placed on the content. Where the content includes any translated material, BMJ does not warrant the accuracy and reliability of the translations (including but not limited to local regulations, clinical guidelines, terminology, drug names and drug dosages), and is not responsible for any error and/or omissions arising from translation and adaptation or otherwise.

Open access This is an open access article distributed in accordance with the Creative Commons Attribution Non Commercial (CC BY-NC 4.0) license, which permits others to distribute, remix, adapt, build upon this work non-commercially, and license their derivative works on different terms, provided the original work is properly cited, appropriate credit is given, any changes made indicated, and the use is non-commercial. See: http://creativecommons.org/licenses/by-nc/4.0/.

ORCID iD

J Maphisa Maphisa http://orcid.org/0000-0003-0716-5812

\section{REFERENCES}

1 Thomas R. Health services planning. New York: Klewar Academic, 2003.

2 World Health Organization. Investing in mental health: evidence for action. World Health organization, 2013. Available: https://apps.who. int/iris/handle/10665/87232 [Accessed 23 May 2020].

3 Vigo DV, Kestel D, Pendakur K, et al. Disease burden and government spending on mental, neurological, and substance use disorders, and self-harm: cross-sectional, ecological study of health system response in the Americas. Lancet Public Health 2019;4:e89-96.

4 Williams DR, Herman A, Kessler RC, et al. The South Africa stress and health study: rationale and design. Metab Brain Dis 2004;19:13-147. 
5 Weiser SD, Leiter K, Heisler M, et al. A population-based study on alcohol and high-risk sexual behaviors in Botswana. PLoS Med 2006;3:e392.

6 Gupta R, Dandu M, Packel L, et al. Depression and HIV in Botswana: a population-based study on gender-specific socioeconomic and behavioral correlates. PLoS One 2010;5:e14252.

7 Hetolang LT, Amone-P'Olak K. The associations between stressful life events and depression among students in a university in Botswana. S Afr J Psychol 2018;48:13-267.

8 Korb I, Plattner IE. Suicide ideation and depression in university students in Botswana. J Psychol Afr 2014;24:420-6.

9 Lewis EL, Mosepele M, Seloilwe E, et al. Depression in HIVpositive women in Gaborone, Botswana. Health Care Women Int 2012;33:375-86.

10 Morutwa G, Plattner IE. Self-Control and alcohol consumption among university students in Botswana. Afr J Drug Alcohol Stud 2014;13:69-78

11 American Psychiatric Association. Diagnostic and statistical manual of mental disorders. 5th ed. Washington: American Psychiatric Association, 2013.

12 Blanco C, Okuda M, Wright C, et al. Mental health of college students and their non-college-attending Peers: results from the National epidemiologic study on alcohol and related conditions. Arch Gen Psychiatry 2008;65:1429-37.

13 Cvetkovski S, Reavley NJ, Jorm AF. The prevalence and correlates of psychological distress in Australian tertiary students compared to their community peers. Aust N Z J Psychiatry 2012;46:457-67.

14 Stallman HM. Psychological distress in university students: a comparison with general population data. Aust Psychol 2010;45:249-57.

15 Auerbach RP, Alonso J, Axinn WG, et al. Mental disorders among college students in the world Health organization world mental health surveys. Psychol Med 2016;46:2955-70.

16 Auerbach RP, Mortier P, Bruffaerts R, et al. Who world mental health surveys international college student project: prevalence and distribution of mental disorders. J Abnorm Psychol 2018;127:623-38.

17 Eisenberg D, Hunt J, Speer N. Mental health in American colleges and universities: variation across student subgroups and across campuses. J Nerv Ment Dis 2013;201:60-7.

18 Bantjes J, Lochner C, Saal W, et al. Prevalence and sociodemographic correlates of common mental disorders among first-year university students in post-apartheid South Africa: implications for a public mental health approach to student wellness. BMC Public Health 2019;19:922.

19 Ibrahim AK, Kelly SJ, Adams CE, et al. A systematic review of studies of depression prevalence in university students. J Psychiatr Res 2013; $47: 391-400$

20 Mall S, Mortier P, Taljaard L, et al. The relationship between childhood adversity, recent stressors, and depression in college students attending a South African university. BMC Psychiatry 2018:18:63

21 Bruffaerts R, Mortier P, Kiekens G, et al. Mental health problems in college freshmen: prevalence and academic functioning. $J$ Affect Disord 2018;225:97-103.

22 Vision 2036 Presidential Task Team (Botswana). Vision 2036: achieving prosperity for all. Gaborone, Botswana: Lentswe La Lesed (Pty) Ltd, 2016: 1-42.

23 Kessler RC, Calabrese JR, Farley PA, et al. Composite international diagnostic interview screening scales for DSM-IV anxiety and mood disorders. Psychol Med 2013;43:1625-37.

24 Masten AS. Developmental psychopathology: pathways to the future. Int J Behav Dev 2006:30:47-54.

25 Masten AS, Faden VB, Zucker RA, et al. Underage drinking: a developmental framework. Pediatrics 2008;121 Suppl 4:S235-51.

26 Statistics Botswana. Population and housing census 2011. Gaborone: Statistics Botswana, 2014.

27 Human Resource Development Council. Tertiary education statistics 2018. Gaborone: Human Resource Development Council, 2019.

28 Greenlaw C, Brown-Welty S. A comparison of web-based and paperbased survey methods: testing assumptions of survey mode and response cost. Eval Rev 2009;33:464-80.

29 Maphisa JM, Young C. Risk of alcohol use disorder among South African university students: the role of drinking motives. Addict Behav 2018;82:44-9.

30 Patridge EF, Bardyn TP. Research electronic data capture (REDCap). Jmla 2018;106.

31 Harris PA, Taylor R, Minor BL, et al. The REDCap Consortium: building an international community of software platform partners. $J$ Biomed Inform 2019;95:103208.
32 Cuijpers P, Auerbach RP, Benjet C, et al. Introduction to the special issue: the who world mental health international college student (WMH-ICS) initiative. Int J Methods Psychiatr Res 2019;28:e1762.

33 Clarke DE, Kuhl EA. Dsm-5 cross-cutting symptom measures: a step towards the future of psychiatric care? World Psychiatry 2014;13:314-6.

34 Bravo AJ, Villarosa-Hurlocker MC, Pearson MR, et al. College student mental health: an evaluation of the DSM-5 self-rated level 1 cross-cutting symptom measure. Psychol Assess 2018;30:1382-9.

35 Narrow WE, Clarke DE, Kuramoto SJ, et al. Dsm-5 field trials in the United States and Canada, part III: development and reliability testing of a cross-cutting symptom assessment for DSM-5. Am J Psychiatry 2013;170:71-82.

36 Meaklim H, Swieca J, Junge M, et al. The DSM-5 self-rated level 1 Cross-Cutting symptom measure identifies high levels of coexistent psychiatric symptomatology in patients referred for insomnia treatment. Nat Sci Sleep 2018;10:377-83.

37 Kroenke K, Spitzer RL, Williams JB. The PHQ-9: validity of a brief depression severity measure. J Gen Intern Med 2001;16:606-13.

38 Altman EG, Hedeker D, Peterson JL, et al. The Altman self-rating mania scale. Biol Psychiatry 1997;42:948-55.

39 Spitzer RL, Kroenke K, Williams JBW, et al. A brief measure for assessing generalized anxiety disorder: the GAD-7. Arch Intern Med 2006;166:1092-7.

40 Connor KM, Kobak KA, Churchill LE, et al. Mini-SPIN: a brief screening assessment for generalized social anxiety disorder. Depress Anxiety 2001;14:137-40.

41 Kroenke K, Spitzer RL, Williams JBW. The PHQ-15: validity of a new measure for evaluating the severity of somatic symptoms. Psychosom Med 2002;64:258-66.

42 Storch EA, Kaufman DAS, Bagner D, et al. Florida obsessivecompulsive inventory: development, reliability, and validity. J Clin Psychol 2007;63:851-9.

43 LeBeau R, Mischel E, Resnick H, et al. Dimensional assessment of posttraumatic stress disorder in DSM-5. Psychiatry Res 2014;218:143-7.

44 Posner K, Brown GK, Stanley B, et al. The Columbia-Suicide severity rating scale: initial validity and internal consistency findings from three multisite studies with adolescents and adults. Am J Psychiatry 2011;168:1266-77.

45 Whitlock J, Eckenrode J, Silverman D. Self-injurious behaviors in a College population. Pediatrics 2006;117:1939-48.

46 Saunders JB, Aasland OG, Babor TF, et al. Development of the Alcohol Use Disorders Identification Test (AUDIT): WHO Collaborative Project on Early Detection of Persons with Harmful Alcohol Consumption--II. Addiction 1993;88:791-804.

47 Adamson SJ, Kay-Lambkin FJ, Baker AL, et al. An improved brief measure of cannabis misuse: the cannabis use disorders identification Test-Revised (CUDIT-R). Drug Alcohol Depend 2010;110:137-43.

48 World Health OrganizationHumeniuk R. The alcohol, smoking and substance involvement screening test (assist): manual for use in primary care. Geneva: World Health Organization, 2010.

49 Parker G, Roussos J, Hadzi-Pavlovic D, et al. The development of a refined measure of dysfunctional parenting and assessment of its relevance in patients with affective disorders. Psychol Med 1997;27:1193-203.

50 World Health Organization. Adverse childhood experiences international questionnaire. in adverse childhood experiences international questionnaire (ACE-IQ), 2018. Available: https://www. who.int/violence_injury_prevention/violence/activities/adverse_ childhood_experiences/en/ [Accessed 22 Apr 2019].

51 Straus MA, Douglas EM. A short form of the revised conflict tactics scales, and typologies for seventy and mutuality. violence and victims, 2004.

52 Fonagy P, Luyten P, Moulton-Perkins A, et al. Development and validation of a self-report measure of mentalizing: the reflective functioning questionnaire. PLoS One 2016;11:e0158678.

53 Baker RW. The student adaptation to College questionnaire and its use in an intervention study with freshmen, 1986.

54 Cooper ML. Motivations for alcohol use among adolescents: development and validation of a four-factor model. Psychol Assess 1994;6:117-28

55 IBM Corp. Statistical package for social science (SPSS) for windows, version 25.0. Amonk, NY, 2017.

56 World Medical Association. World Medical association Declaration of Helsinki: ethical principles for medical research involving human subjects. JAMA 2013;310:2191-4. 